\title{
The major risk factors for delirium in a clinical setting
}

\author{
This article was published in the following Dove Press journal: \\ Neuropsychiatric Disease and Treatment \\ 21 July 2016 \\ Number of times this article has been viewed
}

\author{
Harin Kim \\ Seockhoon Chung \\ Yeon $\mathrm{Ho}$ Joo \\ Jung Sun Lee \\ Department of Psychiatry, Asan \\ Medical Center, University of Ulsan \\ College of Medicine, Seoul, Korea
}

Correspondence: Jung Sun Lee Department of Psychiatry, Asan Medical Center, University of Ulsan College of Medicine, 88 Olympic-ro 43-gil, Songpa-gu, Seoul 05505, Korea Fax +82 24858381

Email js_lee@amc.seoul.kr
Objective: We aimed to determine the major risk factors for the development of delirium in patients at a single general hospital by comparison with a control group.

Subjects and methods: We reviewed the medical records of 260 delirium patients and 77 control patients. We investigated age, sex, and risk factors for delirium in the total delirium group $(n=260)$, the delirium medical subgroup $(n=142)$, and the delirium surgical subgroup $(n=118)$. Logistic regression analysis adjusting for age and sex was performed to identify the odds ratio.

Results: The mean age and the percentage of males were significantly higher in the delirium group compared with the control group (68.9 vs 54.3 years and $70 \%$ vs $41.6 \%$, respectively). Risk factors for the delirium group were lower plasma albumin, hypertension, mechanical ventilation, and antipsychotic drug use. Plasma sodium level and hypertension were important risk factors for the delirium medical subgroup. Stroke history, hypertension, ICU care, and medication were important risk factors for the delirium surgical subgroup.

Conclusion: Lower plasma albumin, hypertension, mechanical ventilation, and antipsychotic drug use are important risk factors for delirium.

Keywords: delirium, acute confusional state, psychiatric consultation, risk factor

\section{Introduction}

The Diagnostic and Statistical Manual of Mental Disorders, Fifth Edition (DSM-5) defines delirium as a disturbance in attention and awareness over a short period of time, representing a change from baseline attention and awareness, with a tendency to fluctuate in severity during the course of a day. ${ }^{1}$ Delirium is a very common disorder affecting $\sim 15 \%$ of medical elderly inpatients. ${ }^{2}$ In a general population study, the prevalence of delirium was $1 \%-2 \%$ in subjects $>65$ years old and $10 \%$ in subjects $>85$ years old. ${ }^{3}$ Patients with delirium have higher mortality and poor long-term prognosis. ${ }^{4,5}$ These results are contrary to the common belief that delirium is a reversible condition and suggest that active intervention should begin at diagnosis due to the adverse effects of delirium on long-term functional outcomes. ${ }^{6-8}$ A recent systematic review of prospective trials suggested that some pharmacological interventions, such as the use of haloperidol, showed success in preventing delirium and in decreasing the duration and/or severity of ongoing delirium, which is associated with better long-term outcomes. ${ }^{9}$

The most important aspect in the treatment and management of delirium is identifying and correcting the underlying causes. The causes of delirium are old age, male sex, underlying cognitive impairment, ${ }^{10,11}$ infection, fever, ${ }^{12,13}$ hypoxia, hypoglycemia, electrolyte imbalance, general medical conditions such as cardiovascular, renal, and hepatic diseases, ${ }^{14}$ use of drugs such as benzodiazepine and narcotic analgesics, ${ }^{15,16}$ metabolic disorders such as encephalopathy, and central nervous system diseases such as stroke, 
traumatic brain injury, and epilepsy. ${ }^{17,18}$ In addition, major surgical procedures such as orthopedic and cardiovascular surgeries, conditions associated with major surgeries such as somatic pain and cobalamin deficiency, ${ }^{19,20}$ and treatment environments such as ICUs are known risk factors. ${ }^{21}$

Most previous studies have investigated individual risk factors for delirium separately in their respective clinical situations. Accordingly, their subjects were limited to those with specific diseases or treatments, and their outcomes identified statistically significant risk factors for delirium. ${ }^{22-30}$ When the results of these studies were compared with a meta-analysis of the risk factors for delirium, some risk factors such as age and the use of benzodiazepine were relatively consistent, but others were not. ${ }^{31-33}$ For example, the presence of hypertension or hypoalbuminemia was not associated with delirium in one prospective study, while other evidence suggests that these factors are associated with delirium. ${ }^{14}$ Few studies have comprehensively examined the reported risk factors, and no study has examined their relative importance.

In this study, we investigated the risk factors for delirium in patients referred for psychiatric consultation, diagnosis, and management. We aimed to identify the risk factors for inpatients who underwent a major surgery under general anesthesia and patients who did not.

\section{Subjects and methods Subjects}

We selected the delirium group and the control group from among patients referred to psychiatrists from August 2013 to July 2014. The delirium group included patients who were interviewed individually by psychiatrists and diagnosed with delirium according to DSM-5 criteria. We excluded patients whose cognitive impairments or psychiatric symptoms were caused by a psychiatric or neurologic disease, such as hallucination, delusion, or abnormal behavior caused by schizophrenia or schizoaffective disorder, or mood symptoms resulting from major mood episodes. We also excluded patients with Alzheimer's disease, vascular dementia, or dementia with Lewy bodies. Patients with substance use disorder were excluded because they might have had a cognitive impairment indistinguishable from delirium. The control group was selected from among patients referred to psychiatrists but not diagnosed with delirium.

Depending on the nature of the psychomotor disturbance and DSM-5 specifier definition, delirium was classified as follows: 1) hyperactive - increased psychomotor activity that may be accompanied by mood lability, agitation, and/or refusal to cooperate with medical care; 2) hypoactive - decreased psychomotor activity that may be accompanied by sluggishness, lethargy, or stupor; or 3) mixed - normal psychomotor activity with disturbed attention and awareness, or rapid fluctuation between hyperactive and hypoactive states of delirium. ${ }^{1}$ Patients were deemed to have psychotic symptoms when further information from caregivers indicated that there was evidence of hallucination or delusion.

The institutional review board of the Asan Medical Center approved the study, including the data collection and analysis. As this study was performed retrospectively, informed consent was not considered necessary by the institutional review board.

\section{Methods}

This study collected data from medical records written by psychiatrists who evaluated the patients. The delirium group was divided into medical and surgical subgroups, each of which was compared with the control group. The delirium medical subgroup included patients who were admitted to the hospital but did not undergo surgery under general anesthesia, while the delirium surgical subgroup included patients who did undergo surgery under general anesthesia. The overall severity of delirium was assessed by the Clinical Global Impression-Severity (CGI-S) scale.

Age, sex, and risk factors for delirium were investigated in the delirium and control groups. Risk factors consistently found in previous studies were comprehensively included and categorized by past medical history, treatment environment, physical illness, and medication history. Past medical history included delirium, dementia, stroke, gait disorder, falling, neurologic diseases, and hypertension. In addition, alcohol use within 1 week before delirium onset was noted, and activities of daily living (ADL) were evaluated on a four-point scale using the caregiver interview conducted by a psychiatrist (1: requires maximum aid for daily living; 2 : requires moderate aid; 3: requires minimum aid; 4: does not require aid).

Treatment environments included ICU treatment and the preventive use of chemical or physical restraints before the occurrence of delirium. Chemical restraint was defined as intravenous or intramuscular injection of a benzodiazepine or an antipsychotic drug, and physical restraint was defined as restraint of the upper or lower limbs. Chemical or physical restraint used for patient safety after the occurrence of delirium was not included as a risk factor.

Physical illness included surgery under general anesthesia after admission, use of mechanical ventilation, and infection. Infection was defined by laboratory tests, the identification of pathogens in bacterial culture, or the empirical use of antibiotics. The patient was considered immobile if he or she was unable to ambulate independently due to a physical 
impairment such as fracture or a neurological disease, or if absolute bed rest was ordered by the medical staff. Renal function was assessed by evaluating the blood urea nitrogen (BUN) and plasma creatinine (CR) levels, and hepatic function was assessed by estimation of blood levels of aspartate transaminase (AST) and alanine transaminase (ALT), as well as plasma albumin levels. Electrolyte imbalance was assessed by determining sodium and potassium levels.

For medication history, all drugs used within 3 days before the occurrence of delirium were explored. The overall number of medications was counted, and the use of antipsychotic drugs, anticholinergic drugs, antiepileptic drugs, and narcotic analgesics was investigated.

\section{Statistical methods}

We compared age, sex, prevalence of psychotic symptoms manifested as hallucinations or delusions, and the frequency of the delirium type between the delirium and control groups. We tried to identify the potential risk factors for delirium in two steps. In Step 1, we used Student's $t$-tests or chi-square tests for demographic and clinical variables. In Step 2, variables with $P<0.1$ in Step 1 were entered into the next analysis of multiple logistic regression. We identified the odds ratio (OR) for each factor's contribution to the occurrence of delirium using multiple logistic regression analysis, with adjustment for age and sex. Statistical analyses were undertaken using SPSS version 18 (IBM Corporation, Armonk, NY, USA), and a $P$-value $<0.05$ was considered statistically significant.

\section{Results}

We included 260 patients in the delirium group and 77 patients in the control group. Among the patients in the delirium group, 142 patients $(54.6 \%)$ were classified into the delirium medical subgroup and 118 patients (45.4\%) into the delirium surgical subgroup. Most of the patients in the control group were diagnosed with major depression, adjustment disorder, sleep disorder, panic disorder, or unspecified anxiety disorder.

The mean age was 68.9 years (standard deviation [SD]: \pm 13.0 years) in the delirium group and 54.3 years (SD: \pm 16.8 years) in the control group. In addition, 182 patients $(70 \%)$ in the delirium group and 32 patients $(41.6 \%)$ in the control group were male. The mean age of the delirium group was significantly higher than that of the control group ( $t=-8.05, P<0.001$ ), and there were more male patients in the delirium group than in the control group (70\% vs $41.6 \%$, $\left.\chi^{2}=20.7, P<0.001\right)$. In the delirium group, 167 patients $(64.2 \%)$ had hyperactive delirium, 18 patients $(6.9 \%)$ had hypoactive delirium, and 75 patients $(28.8 \%)$ had mixed delirium. Regarding psychotic symptoms, 91 patients (35\%) experienced hallucination and 52 patients $(20 \%)$ experienced delusion. The mean severity was a Clinical Global ImpressionSeverity scale (CGI-S) score of 4.0.

There were no significant differences in terms of age, sex, type of delirium, frequency of psychotic symptoms, or CGI-S score between the two subgroups. There was a significant difference in age between the medical subgroup $(69.3 \pm 13.9$ years, $t=-7.06, P<0.001)$ and the surgical subgroup $(68.4 \pm 11.9$ years, $t=-6.86, P<0.001)$ compared with the control group $(54.3 \pm 16.8$ years $)$. There were more male patients in the medical subgroup $\left(70.4 \%, \chi^{2}=17.37, P<0.001\right)$ and the surgical subgroup $\left(69.5 \%, \chi^{2}=14.97, P<0.001\right)$ than in the control group (41.6\%) (Table 1$)$.

In Step 1, we identified the potential risk factors by comparison with the control group: 1) By comparing the delirium group with the control group, we could find out that ADL score, the BUN, CR, and plasma albumin levels number of medications, past history of delirium and stroke, ICU care, hypertension, mechanical ventilation, infection, immobility, and use of antipsychotic drugs were the potential risk factors of delirium in the delirium group. 2) By comparing the delirium medical subgroup with the control group, we could find out that ADL score, the BUN, CR, plasma albumin, and plasma sodium levels, past history of delirium and stroke, past history of falls, hypertension, mechanical ventilation, infection, and use of antipsychotic drugs were the potential risk factors of delirium in the delirium medical subgroup. 3) By comparing the delirium surgical subgroup with the control group, we could find out that ADL score, the BUN, CR, and plasma albumin levels, number of medications, past history of delirium and stroke, ICU care, hypertension, mechanical ventilation, immobility, and the use of antipsychotic drugs, anticholinergic drugs, and opioids were the potential risk factors of delirium in the delirium surgical subgroup (Tables 2 and 3).

In Step 2, we identified the risk factors for delirium after multiple logistic regression, after controlling for age and sex (results are presented as OR, 95\% confidence interval [CI]): 1) In the delirium group, plasma albumin level (0.55, 0.32-0.94), hypertension $(2.86,1.21-6.72)$, mechanical ventilation $(12.49,1.13-138.00)$, and use of antipsychotic drugs $(4.07,1.41-11.72)$; 2$)$ In the delirium medical subgroup, plasma sodium level $(0.90,0.83-0.98)$ and hypertension (2.91, 1.12-7.55); and 3) In the delirium surgical subgroup, plasma albumin level (0.37, 0.16-0.87), number of medications $(1.09,1.00-1.18)$, past history of stroke (1,817.71, 5.37-614,920.5), ICU care (17.95, 1.96-164.55), hypertension (5.90, 1.39-25.09), and the use of antipsychotic drugs (14.57, 2.93-72.37), anticholinergic drugs (14.50, 1.57-134.14), and opioids (6.10, 1.58-23.44) (Table 4). 
Table I Characteristics of the delirium and control groups

\begin{tabular}{|c|c|c|c|c|c|c|c|c|}
\hline \multirow[t]{2}{*}{ Characteristics } & \multicolumn{3}{|c|}{ Delirium group } & \multirow{2}{*}{$\begin{array}{l}\text { Control } \\
\text { group }\end{array}$} & \multicolumn{4}{|l|}{$P$-value } \\
\hline & Total & $\begin{array}{l}\text { Medical } \\
\text { subgroup }\end{array}$ & $\begin{array}{l}\text { Surgical } \\
\text { subgroup }\end{array}$ & & $\begin{array}{l}\text { Total vs } \\
\text { control }\end{array}$ & $\begin{array}{l}\text { Medical } \\
\text { subgroup } \\
\text { vs control }\end{array}$ & $\begin{array}{l}\text { Surgical } \\
\text { subgroup } \\
\text { vs control }\end{array}$ & $\begin{array}{l}\text { Medical } \\
\text { subgroup } \\
\text { vs surgical } \\
\text { subgroup }\end{array}$ \\
\hline Number of patients, n (\%) & 260 & $142(54.6 \%)$ & II 8 (45.4\%) & 77 & - & - & - & - \\
\hline Age, years, mean \pm SD & $68.9 \pm 13.0$ & $69.3 \pm 13.9$ & $68.4 \pm 11.9$ & $54.3 \pm 16.8$ & $\begin{array}{l}t=-8.05 \\
P<0.001\end{array}$ & $\begin{array}{l}t=-7.06 \\
P<0.001\end{array}$ & $\begin{array}{l}t=-6.86 \\
P<0.001\end{array}$ & $\begin{array}{l}t=0.52 \\
P=0.603\end{array}$ \\
\hline Male sex, n (\%) & I $82(70.0 \%)$ & 100 (70.4\%) & $82(69.5 \%)$ & $32(41.6 \%)$ & $\begin{array}{l}\chi^{2}=20.7 \\
P<0.001\end{array}$ & $\begin{array}{l}\chi^{2}=17.37 \\
P<0.001\end{array}$ & $\begin{array}{l}\chi^{2}=14.97 \\
P<0.001\end{array}$ & $\begin{array}{l}\chi^{2}=0.027 \\
P=0.87\end{array}$ \\
\hline \multicolumn{9}{|l|}{ Psychotic symptoms } \\
\hline Hallucination, n (\%) & $91(35.0 \%)$ & 47 (33.1\%) & 44 (37.6\%) & - & - & - & - & $\begin{array}{l}\chi^{2}=0.57 \\
P=0.449\end{array}$ \\
\hline Delusion, n (\%) & $52(20.0 \%)$ & 31 (2I.8\%) & $21(18.0 \%)$ & - & - & - & - & $\begin{array}{l}\chi^{2}=0.603 \\
P=0.438\end{array}$ \\
\hline CGI-S score, mean \pm SD & $3.99 \pm 0.8$ & $4.01 \pm 0.88$ & $3.96 \pm 0.81$ & - & - & - & - & $\begin{array}{l}t=0.395 \\
P=0.693\end{array}$ \\
\hline \multicolumn{9}{|l|}{ Type of delirium } \\
\hline Hyperactive, n (\%) & $167(64.2 \%)$ & 90 (63.4\%) & 77 (65.3\%) & - & - & - & - & $\chi^{2}=1.28$ \\
\hline Hypoactive, n (\%) & $18(6.9 \%)$ & $8(5.6 \%)$ & $10(8.5 \%)$ & - & - & - & - & $P=0.526$ \\
\hline Mixed, n (\%) & 75 (28.8\%) & 44 (31.0\%) & 31 (26.3\%) & - & - & - & - & - \\
\hline
\end{tabular}

Abbreviations: CGI-S, Clinical Global Impression - Severity scale; SD, standard deviation.

\section{Discussion}

In this study, the mean age of the subjects in the delirium group was 14.6 years, which was greater than that of the control group, and $70 \%$ of the delirium group comprised males, whereas only $41.6 \%$ of the control group were males. This was concordant with previous reports that identified age and male sex as the major risk factors for the development of delirium. ${ }^{10,11,34}$ Age and sex, which are unmodifiable through medical intervention, are demographic risk factors for delirium. However, this study was designed to identify the significant risk factors for delirium across a wide range of clinical settings and to evaluate the OR of each risk factor. Therefore, we adjusted for age and sex in the logistic regression in Step 2.

Among the psychomotor disturbance subtypes, hyperactive delirium was the most common (64.2\%), while hypoactive delirium was the least common $(6.9 \%)$. This result contrasts with the general opinion that mixed delirium is the

Table 2 Comparison between delirium group and control group in terms of risk factors for delirium (continuous variables)

\begin{tabular}{|c|c|c|c|c|c|c|c|}
\hline \multirow[t]{2}{*}{ Risk factors } & \multicolumn{3}{|c|}{ Delirium group $(n=260)$, mean $\pm S D$} & \multirow{2}{*}{$\begin{array}{l}\text { Control } \\
\text { group }(n=77), \\
\text { mean } \pm \text { SD }\end{array}$} & \multicolumn{3}{|c|}{$\begin{array}{l}\text { Comparisons between delirium group } \\
\text { and control group ( } P \text {-value })\end{array}$} \\
\hline & Total & $\begin{array}{l}\text { Medical } \\
\text { subgroup }\end{array}$ & $\begin{array}{l}\text { Surgical } \\
\text { subgroup }\end{array}$ & & $\begin{array}{l}\text { Total } \\
\text { delirium } \\
\text { vs control }\end{array}$ & $\begin{array}{l}\text { Medical } \\
\text { subgroup } \\
\text { vs control }\end{array}$ & $\begin{array}{l}\text { Surgical } \\
\text { subgroup } \\
\text { vs delirium } \\
\end{array}$ \\
\hline \multicolumn{8}{|l|}{ Past medical history } \\
\hline ADL score & $3.2 \pm 0.9$ & $3.03 \pm 1.01$ & $3.4 \pm 0.80$ & $3.7 \pm 0.6$ & 0.0001 & $<0.0001$ & 0.0308 \\
\hline \multicolumn{8}{|l|}{ Physical illness } \\
\hline BUN (mg/dL) & $24.1 \pm 15.0$ & $24.8 \pm 15.0$ & $23.2 \pm 15.0$ & $18.3 \pm 13.8$ & 0.0026 & 0.0018 & 0.0226 \\
\hline Creatinine (mg/dL) & $1.6 \pm 1.9$ & $1.7 \pm 2.0$ & $1.5 \pm 1.7$ & $1.1 \pm 1.1$ & 0.0105 & 0.0059 & 0.0410 \\
\hline AST (IU/L) & $46.4 \pm 91.6$ & $42.8 \pm 42.4$ & $50.8 \pm 128.0$ & $46.0 \pm 66.3$ & 0.9729 & 0.6596 & 0.7639 \\
\hline ALT (IU/L) & $42.8 \pm 104.4$ & $40.3 \pm 53.5$ & $45.9 \pm 143.8$ & $42.6 \pm 67.2$ & $0.987 \mid$ & 0.7762 & 0.8508 \\
\hline Albumin $(g / d L)$ & $2.7 \pm 0.6$ & $2.7 \pm 0.6$ & $2.8 \pm 0.7$ & $3.2 \pm 0.7$ & $<0.0001$ & $<0.0001$ & 0.0001 \\
\hline Sodium (mmol/L) & $136.7 \pm 10.0$ & $135.5 \pm 12.5$ & $|38| \pm 5.4$. & $138.5 \pm 4.2$ & 0.1118 & 0.041 & 0.5230 \\
\hline Potassium (mmol/L) & $4.1 \pm 0.6$ & $4 . I \pm 0.7$ & $4 . I \pm 0.6$ & $4.2 \pm 0.6$ & 0.2631 & 0.2779 & 0.3546 \\
\hline \multicolumn{8}{|l|}{ Medication history } \\
\hline Number of drugs & $11.5 \pm 6.3$ & $10.4 \pm 4.7$ & $12.8 \pm 7.6$ & $9.5 \pm 4.9$ & 0.0093 & 0.1599 & 0.0008 \\
\hline
\end{tabular}

Abbreviations: ADL, activities of daily living; BUN, blood urea nitrogen; AST, aspartate transaminase; ALT, alanine transaminase; SD, standard deviation. 
Table 3 Comparison between delirium group and control group in terms of risk factors for delirium (categorical variables)

\begin{tabular}{|c|c|c|c|c|c|c|c|}
\hline \multirow[t]{2}{*}{ Risk factors } & \multicolumn{3}{|c|}{ Delirium group $(n=260), n(\%)$} & \multirow[t]{2}{*}{$\begin{array}{l}\text { Control, } \\
\text { n (\%) }\end{array}$} & \multicolumn{3}{|c|}{$\begin{array}{l}\text { Comparisons between delirium group } \\
\text { and control group ( } P \text {-value) }\end{array}$} \\
\hline & Total & $\begin{array}{l}\text { Medical } \\
\text { subgroup }\end{array}$ & $\begin{array}{l}\text { Surgical } \\
\text { subgroup }\end{array}$ & & $\begin{array}{l}\text { Total } \\
\text { delirium } \\
\text { vs control }\end{array}$ & $\begin{array}{l}\text { Medical } \\
\text { subgroup } \\
\text { vs control }\end{array}$ & $\begin{array}{l}\text { Surgical } \\
\text { subgroup } \\
\text { vs control }\end{array}$ \\
\hline \multicolumn{8}{|l|}{ Past medical history } \\
\hline Past delirium history & $59(22.7)$ & $26(18.3)$ & $33(28.0)$ & $4(5.2)$ & 0.001 & 0.007 & $<0.001$ \\
\hline Dementia history & $10(3.9)$ & $5(3.5)$ & $5(4.2)$ & $\mathrm{I}(\mathrm{I} .3)$ & 0.269 & 0.336 & 0.245 \\
\hline Stroke history & $26(10)$ & $10(7.04)$ & $16(13.56)$ & I (I.3) & 0.013 & 0.063 & 0.003 \\
\hline Ambulation difficulty & $42(16.2)$ & $24(16.9)$ & $18(15.3)$ & $8(10.4)$ & 0.211 & 0.193 & 0.329 \\
\hline Falling history & $18(6.9)$ & $13(9.15)$ & $5(4.24)$ & $2(2.6)$ & 0.158 & 0.067 & 0.547 \\
\hline Past neurologic history & $39(15.0)$ & $23(16.2)$ & $16(13.6)$ & II (I4.3) & 0.877 & 0.709 & 0.886 \\
\hline Hypertension & $124(47.7)$ & $67(47.2)$ & $57(48.3)$ & $12(15.6)$ & $<0.001$ & $<0.001$ & $<0.001$ \\
\hline Alcohol use & $9(3.5)$ & $3(2.1)$ & $6(5.1)$ & $3(3.9)$ & 0.857 & 0.440 & 0.699 \\
\hline \multicolumn{8}{|l|}{ Treatment environment } \\
\hline ICU care & $66(25.4)$ & $29(20.4)$ & $37(31.4)$ & $9(11.7)$ & 0.011 & 0.103 & 0.002 \\
\hline Chemical restraint & $76(29.2)$ & $38(26.8)$ & $38(32.2)$ & $0(0)$ & $<0.001$ & $<0.001$ & $<0.001$ \\
\hline Physical restraint & $49(18.9)$ & $21(14.8)$ & $28(23.7)$ & $0(0)$ & $<0.001$ & $<0.001$ & $<0.001$ \\
\hline \multicolumn{8}{|l|}{ Physical illness } \\
\hline Surgery & I $18(45.4)$ & 0 & $118(100)$ & $13(16.9)$ & & & \\
\hline Mechanical ventilation & $34(13.1)$ & $20(14 . I)$ & $14(11.9)$ & $\mathrm{I}(\mathrm{I} .3)$ & 0.003 & 0.002 & 0.007 \\
\hline Infection & $122(46.9)$ & $83(58.5)$ & $39(33.1)$ & $18(23.4)$ & $<0.001$ & $<0.001$ & 0.147 \\
\hline Immobility & $92(35.4)$ & $48(33.8)$ & $44(37.3)$ & $8(10.4)$ & $<0.001$ & $<0.001$ & $<0.001$ \\
\hline \multicolumn{8}{|l|}{ Medication history } \\
\hline Antipsychotic drug use & $102(39.2)$ & $50(35.2)$ & $52(44.1)$ & $6(7.8)$ & $<0.001$ & $<0.001$ & $<0.001$ \\
\hline Anticholinergic drug use & $26(10.0)$ & $9(6.3)$ & $17(14.4)$ & $4(5.2)$ & 0.193 & 0.732 & 0.043 \\
\hline Anticonvulsant use & $24(9.2)$ & II (7.8) & $13(11.0)$ & $5(6.5)$ & 0.452 & 0.734 & 0.286 \\
\hline Opioid use & $126(48.5)$ & $59(4 \mid .6)$ & $67(56.8)$ & $33(42.9)$ & 0.387 & 0.851 & 0.057 \\
\hline
\end{tabular}

Abbreviation: ICU, intensive care unit.

Table 4 Multiple logistic regression of risk factors for delirium

\begin{tabular}{|c|c|c|c|c|c|c|c|c|c|}
\hline \multirow[t]{2}{*}{ Risk factors } & \multicolumn{3}{|c|}{ Total delirium vs control } & \multicolumn{3}{|c|}{ Medical subgroup vs control } & \multicolumn{3}{|c|}{ Surgical subgroup vs control } \\
\hline & OR & $95 \% \mathrm{Cl}$ & P-value & OR & $95 \% \mathrm{Cl}$ & $P$-value & OR & $95 \% \mathrm{Cl}$ & $P$-value \\
\hline \multicolumn{10}{|l|}{ Past medical history } \\
\hline Past delirium history & 2.90 & $0.90-11.97$ & 0.142 & 3.68 & $0.62-21.70$ & 0.150 & 7.47 & $0.87-63.87$ & 0.066 \\
\hline Past history of stroke & 8.98 & $0.48-168.04$ & 0.142 & 3.19 & $0.08-121.62$ & 0.533 & $\mathrm{I}, 8|7.7| *$ & $5.37-6 \mid 4,920.5$ & 0.012 \\
\hline Past history of falls & - & - & - & 0.98 & $0.14-6.99$ & 0.981 & - & - & - \\
\hline \multicolumn{10}{|l|}{ Treatment environment } \\
\hline ICU care & 1.82 & $0.56-5.92$ & 0.321 & - & - & - & $17.95^{*}$ & $1.96-164.55$ & 0.011 \\
\hline Hypertension & $2.86 *$ & $1.21-6.72$ & 0.016 & $2.91 *$ & I.12-7.55 & 0.028 & $5.90 *$ & $1.39-25.09$ & 0.016 \\
\hline Mechanical ventilation & $12.49 *$ & $1.13-138.00$ & 0.039 & 10.04 & $0.97-104.21$ & 0.053 & 6.80 & $0.29-157.28$ & 0.232 \\
\hline Infection & 2.01 & $0.87-4.63$ & 0.103 & 2.49 & $0.98-6.33$ & 0.055 & - & - & - \\
\hline Immobility & 2.61 & $0.90-7.55$ & 0.077 & 2.92 & $0.88-9.71$ & 0.080 & 2.12 & $0.40-11.15$ & 0.375 \\
\hline \multicolumn{10}{|l|}{ Physical illness } \\
\hline ADL score & 0.86 & $0.52-1.42$ & 0.554 & 0.67 & $0.37-1.18$ & 0.165 & 0.79 & $0.39-1.61$ & 0.518 \\
\hline BUN & 1.00 & $0.97-1.03$ & 0.997 & 1.01 & $0.98-1.04$ & $0.56 \mathrm{I}$ & 1.00 & $0.94-1.05$ & 0.855 \\
\hline CR & 1.15 & $0.813-1.64$ & 0.422 & 1.13 & $0.80-1.61$ & 0.479 & 0.92 & $0.53-1.61$ & 0.782 \\
\hline Albumin & $0.55^{*}$ & $0.32-0.94$ & 0.028 & 0.63 & $0.33-1.21$ & 0.165 & $0.37^{*}$ & $0.16-0.87$ & 0.022 \\
\hline Sodium & - & - & - & $0.90^{*}$ & $0.83-0.98$ & 0.010 & - & - & - \\
\hline \multicolumn{10}{|l|}{ Medication history } \\
\hline Number of medications & 1.06 & $0.99-1.15$ & 0.1 & - & - & - & $1.09 *$ & $1.00-1.18$ & 0.050 \\
\hline Antipsychotic drug use & $4.07^{*}$ & $1.41-11.72$ & 0.009 & 2.38 & $0.73-7.81$ & 0.151 & $14.57^{*}$ & $2.93-72.37$ & 0.001 \\
\hline Anticholinergic drug use & - & - & - & - & - & - & $14.50 *$ & $1.57-134.14$ & 0.018 \\
\hline Opioid use & - & - & - & - & - & - & $6.10 *$ & $1.58-23.44$ & 0.009 \\
\hline
\end{tabular}

Note: $* p<0.05$

Abbreviations: ADL, activities of daily living; BUN, blood urea nitrogen; $\mathrm{Cl}$, confidence interval; $\mathrm{CR}$, creatinine; ICU, intensive care unit; OR, odds ratio. 
most common delirium subtype. ${ }^{35}$ This discrepancy may be due to the fact that hypoactive delirium is difficult for medical staff to identify and is easily missed. The natural course of delirium fluctuates, and assessment is often made when the symptoms have become aggravated, leading to a determination of hyperactive delirium. According to a recent study, ${ }^{36}$ one of the major reasons that nurses fail to detect delirium is that the natural course of delirium changes. Because we included patients who had been referred to psychiatrists, there was a greater chance of including patients whose behavioral problems were relatively severe and easily noticeable.

In order to identify the risk factors in two major clinical situations, we categorized the delirium group into medical and surgical subgroups. Lower albumin level, hypertension, mechanical ventilation, and use of antipsychotic drugs were identified as risk factors in the delirium group. Among these factors, lower albumin level, hypertension, and use of antipsychotic drugs are modifiable through proper medical care, and it might be important to correct these risk factors aggressively to prevent and/or manage delirium. A recent metaanalysis determined that the risk of delirium can be lowered in surgical inpatients by the preventive use of antipsychotic drugs. ${ }^{37}$ However, the use of antipsychotic drugs did not have a significant effect on the duration of delirium, the severity of symptoms, or the length of hospital stay. ${ }^{37}$ In contrast, another study reported that the use of antipsychotic drugs in ICU patients without a specific diagnosis might increase the duration of hospital stay and mortality. ${ }^{38}$ Clearly, the effect of antipsychotic drugs on delirium requires further research.

When we identified the risk factors for delirium in the two subgroups, there were some differences. While the risk factors in the medical subgroup were lower plasma sodium level and hypertension, the risk factors in the surgical subgroup were lower plasma albumin level, past history of stroke, ICU care, hypertension, number of medications, and the use of antipsychotic drugs, anticholinergic drugs, and opioids. The fact that the two subgroups showed different results suggests that different risk factors should be considered in each clinical situation. For nonsurgical patients, it might be important to control electrolyte imbalance. For surgical patients, surgery is a known risk factor for delirium, and delirium is believed to be associated with preoperative and postoperative stroke in patients with risk factors for cardiovascular diseases. ${ }^{39-42}$ Furthermore, postoperative surgical patients are often treated in the ICU, which itself is a risk factor for delirium. Thus, stroke prevention should be a priority in surgical management.

This study had several limitations of note. First, we could not clarify the temporal relation between risk factors and the occurrence of delirium because of the cross-sectional study design. However, this limitation was minimized by the fact that we collected the risk factor information prior to the onset of delirium. Second, the etiology of delirium is multifactorial and has not been completely clarified. In addition to the risk factors included in this study, there might be unidentified or inconsistently reported risk factors that were not included. Because we could not process the information about medication use appropriately, the effect of medication history on the development of delirium might have been underestimated. Third, the control group and the delirium group were not precisely matched. There were differences in physical illness and major procedures such as surgery under anesthesia. It was difficult to enroll matched controls who had no psychiatric problems and, accordingly, to obtain information from psychiatric assessments for them. To reduce the effect of the control group differences, however, we excluded certain risk factors. For example, we excluded the use of benzodiazepines in the analysis as we were certain that the control group had a higher rate of use. Nevertheless, the results should be cautiously interpreted. Fourth, because the number of patients involved in our study is limited, it is difficult to extrapolate the results to the general population. Moreover, some risk factors (mechanical ventilation and past history of stroke) showed wide CI of the ORs. It may be due to the small number of patients who had risk factors. The results with wide CI should be cautiously interpreted because these results may lose their statistical significance in other studies.

We attempted to overcome the limitations of previous studies by including various risk factors of delirium. We were able to identify significant risk factors under general clinical situations, ie, the study was not limited to one specific clinical setting. Furthermore, we investigated both the delirium group and the control group for the same risk factors. The use of the control group for the analysis is one strength of our study.

\section{Disclosure}

The authors report no conflicts of interest in this work.

\section{References}

1. American Psychiatric Association. Diagnostic and Statistical Manual of Mental Disorders (DSM-5). Arlington, VA: American Psychiatric Association; 2013.

2. Bucht G, Gustafson Y, Sandberg O. Epidemiology of delirium. Dement Geriatr Cogn Disord. 1999;10(5):315-318.

3. de Lange E, Verhaak PF, van der Meer K. Prevalence, presentation and prognosis of delirium in older people in the population, at home and in long term care: a review. Int J Geriatr Psychiatry. 2013;28(2):127-134.

4. Tsai MC, Weng HH, Chou SY, Tsai CS, Hung TH, Su JA. Three-year mortality of delirium among elderly inpatients in consultation-liaison service. Gen Hosp Psychiatry. 2012;34(1):66-71. 
5. Miu DK, Yeung JC. Incidence of post-stroke delirium and 1-year outcome. Geriatr Gerontol Int. 2013;13(1):123-129.

6. Wolters AE, van Dijk D, Pasma W, et al. Long-term outcome of delirium during intensive care unit stay in survivors of critical illness: a prospective cohort study. Crit Care. 2014;18(3):R125.

7. Dasgupta M, Brymer C. Prognosis of delirium in hospitalized elderly: worse than we thought. Int J Geriatr Psychiatry. 2014;29(5):497-505.

8. Saczynski JS, Marcantonio ER, Quach L, et al. Cognitive trajectories after postoperative delirium. $N$ Engl J Med. 2012;367(1):30-39.

9. Friedman JI, Soleimani L, McGonigle DP, Egol C, Silverstein JH. Pharmacological treatments of non-substance-withdrawal delirium: a systematic review of prospective trials. Am J Psychiatry. 2014;171(2):151-159.

10. Fortini A, Morettini A, Tavernese G, Facchini S, Tofani L, Pazzi M. Delirium in elderly patients hospitalized in internal medicine wards. Intern Emerg Med. 2014;9(4):435-441.

11. Nagase M, Okamoto $Y$, Tsuneto $S$, et al. A retrospective chart review of terminal patients with cancer with agitation and their risk factors. $J$ Palliat Med. 2012;15(11):1185-1190.

12. Pol RA, van Leeuwen BL, Izaks GJ, et al. C-reactive protein predicts postoperative delirium following vascular surgery. Ann Vasc Surg. 2014; 28(8):1923-1930.

13. Ritchie CW, Newman TH, Leurent B, Sampson EL. The association between C-reactive protein and delirium in 710 acute elderly hospital admissions. Int Psychogeriatr. 2014;26(5):717-724.

14. Aldemir M, Ozen S, Kara IH, Sir A, Baç B. Predisposing factors for delirium in the surgical intensive care unit. Crit Care. 2001;5(5):265-270.

15. Rothberg MB, Herzig SJ, Pekow PS, Avrunin J, Lagu T, Lindenauer PK. Association between sedating medications and delirium in older inpatients. J Am Geriatr Soc. 2013;61(6):923-930.

16. Tse L, Schwarz SK, Bowering JB, et al. Pharmacological risk factors for delirium after cardiac surgery: a review. Curr Neuropharmacol. 2012; 10(3):181-196.

17. Shi Q, Presutti R, Selchen D, Saposnik G. Delirium in acute stroke: a systematic review and meta-analysis. Stroke. 2012;43(3):645-649.

18. Nakase-Thompson R, Sherer M, Yablon SA, Nick TG, Trzepacz PT. Acute confusion following traumatic brain injury. Brain Inj. 2004;18(2): 131-142.

19. Xue P, Wu Z, Wang K, Tu C, Wang X. Incidence and risk factors of postoperative delirium in elderly patients undergoing transurethral resection of prostate: a prospective cohort study. Neuropsychiatr Dis Treat. 2016; 12:137-142.

20. Sevuk U, Baysal E, Ay N, et al. Relationship between cobalamin deficiency and delirium in elderly patients undergoing cardiac surgery. Neuropsychiatr Dis Treat. 2015;11:2033-2039.

21. Van Rompaey B, Elseviers MM, Schuurmans MJ, Shortridge-Baggett LM, Truijen S, Bossaert L. Risk factors for delirium in intensive care patients: a prospective cohort study. Crit Care. 2009;13(3):R77.

22. Leite MA, Osaku EF, Costa CR, et al. Delirium during weaning from mechanical ventilation. Crit Care Res Pract. 2014;2014:546349.

23. Ahmed S, Leurent B, Sampson EL. Risk factors for incident delirium among older people in acute hospital medical units: a systematic review and meta-analysis. Age Ageing. 2014;43(3):326-333.

24. Kanbayashi Y, Hatano Y, Hata Y, Morita T, Fukui K, Hosokawa T Predictive factors for agitation severity of hyperactive delirium in terminally ill cancer patients in a general hospital using ordered logistic regression analysis. J Palliat Med. 2013;16(9):1020-1025.
25. de Castro SM, Ünlü Ç, Tuynman JB, et al. Incidence and risk factors of delirium in the elderly general surgical patient. Am J Surg. 2014;208(1): 26-32.

26. Gallagher TK, McErlean S, O'Farrell A, et al. Incidence and risk factors of delirium in patients post pancreaticoduodenectomy. HPB (Oxford). 2014;16(9):864-869.

27. Krzych LJ, Wybraniec MT, Krupka-Matuszczyk I, et al. Complex assessment of the incidence and risk factors of delirium in a large cohort of cardiac surgery patients: a single-center 6-year experience. Biomed Res Int. 2013;2013:835850.

28. Shadvar K, Baastani F, Mahmoodpoor A, Bilehjani E. Evaluation of the prevalence and risk factors of delirium in cardiac surgery ICU. J Cardiovasc Thorac Res. 2013;5(4):157-161.

29. Serafim RB, Dutra MF, Saddy F, et al. Delirium in postoperative nonventilated intensive care patients: risk factors and outcomes. Ann Intensive Care. 2012;2(1):51.

30. Lee HJ, Hwang DS, Wang SK, Chee IS, Baeg S, Kim JL. Early assessment of delirium in elderly patients after hip surgery. Psychiatry Investig. 2011;8(4):340-347.

31. Lin Y, Chen J, Wang Z. Meta-analysis of factors which influence delirium following cardiac surgery. J Card Surg. 2012;27(4):481-492.

32. Huai J, Ye X. A meta-analysis of critically ill patients reveals several potential risk factors for delirium. Gen Hosp Psychiatry. 2014;36(5): 488-496.

33. van Munster BC, de Rooij SE. Delirium: a synthesis of current knowledge. Clin Med. 2014;14(2):192-195.

34. Inouye SK. Delirium in older persons. N Engl J Med. 2006;354(11): 1157-1165.

35. Liptzin B, Levkoff SE. An empirical study of delirium subtypes. Br J Psychiatry. 1992;161:843-845.

36. El Hussein M, Hirst S, Salyers V. Factors that contribute to underrecognition of delirium by registered nurses in acute care settings: a scoping review of the literature to explain this phenomenon. J Clin Nurs. 2015;24(7-8):906-915.

37. Gilmore ML, Wolfe DJ. Antipsychotic prophylaxis in surgical patients modestly decreases delirium incidence - but not duration - in highincidence samples: a meta-analysis. Gen Hosp Psychiatry. 2013;35(4): 370-375.

38. Swan JT, Fitousis K, Hall JB, Todd SR, Turner KL. Antipsychotic use and diagnosis of delirium in the intensive care unit. Crit Care. 2012; $16(3): R 84$

39. Wong GY, Warner DO, Schroeder DR, et al. Risk of surgery and anesthesia for ischemic stroke. Anesthesiology. 2000;92(2):425-432.

40. Bucerius J, Gummert JF, Borger MA, et al. Stroke after cardiac surgery: a risk factor analysis of 16,184 consecutive adult patients. Ann Thorac Surg. 2003;75(2):472-478.

41. Whitlock R, Healey JS, Connolly SJ, et al. Predictors of early and late stroke following cardiac surgery. CMAJ. 2014;186(12):905-911.

42. Brooks DC, Schindler JL. Perioperative stroke: risk assessment, prevention and treatment. Curr Treat Options Cardiovasc Med. 2014; 16(2):282.
Neuropsychiatric Disease and Treatment

\section{Publish your work in this journal}

Neuropsychiatric Disease and Treatment is an international, peerreviewed journal of clinical therapeutics and pharmacology focusing on concise rapid reporting of clinical or pre-clinical studies on a range of neuropsychiatric and neurological disorders. This journa is indexed on PubMed Central, the 'PsycINFO' database and CAS,

\section{Dovepress}

and is the official journal of The International Neuropsychiatric Association (INA). The manuscript management system is completely online and includes a very quick and fair peer-review system, which is all easy to use. Visit http://www.dovepress.com/testimonials.php to read real quotes from published authors. 